\title{
Slow earthquakes and low frequency tremor along the Apennines, Italy
}

\author{
Roberto Scarpa $\left({ }^{1}\right)\left({ }^{2}\right)$, Antonella Amoruso $\left({ }^{3}\right)$, Luca Crescentini $\left({ }^{3}\right)$, Costantino Fischione $\left({ }^{2}\right)$, Luisa Anna \\ Formisano $\left({ }^{3}\right)$, Mario La Rocca $\left({ }^{2}\right)$ and Fabrizio Tronca $\left({ }^{2}\right)$ \\ ( $\left.{ }^{1}\right)$ Dipartimento di Matematica ed Informatica, Università degli Studi di Salerno, Italy \\ $\left.{ }^{(}\right)$Istituto Nazionale di Geofisica e Vulcanologia, Osservatorio Vesuviano, Italy \\ $\left.{ }^{3}\right)$ Dipartimento di Fisica, Università degli Studi di Salerno, Italy
}

\begin{abstract}
This paper reviews the main observations on slow earthquakes and low frequency tremor made along the Apennines, the main seismic active zone of Italy. These observations have been made using a geodetic interferometer system operating since 1994 in the underground tunnel of Gran Sasso, central Italy, and an underground seismic array (UNDERSEIS) operating since 2002 in the same environment.

The observations made in recent years indicate that both phenomena are quite rare and apparently uncorrelated. Slow earthquakes, mainly recorded in 1997 and occasionally later, have probably been caused by the activity of a shallow fault system located near the interferometers. Until now only one tremor episode characterized by low frequency content and duration of several hours has been detected in January 2004, without any correlations with the occurrence of slow or regular earthquakes. The signal to noise ratio of this event is very low, but the results of our detailed analysis show that its frequency contents and wave field characteristics are compatible with a low frequency non volcanic tremor.
\end{abstract}

Key words Slow earthquakes - Tremor - Apennines

\section{Introduction}

An expanding series of unusual seismic phenomena have recently been observed, including deep episodic tremor, low-frequency earthquakes, very-lowfrequency earthquakes, slow slip events and silent earthquakes. Each of these has been modelled to arise from shear slip, like regular earthquakes, but with longer characteristic durations and radiating much less

Mailing address: Dr. Roberto Scarpa, Dipartimento di Matematica ed Informatica, Università degli Studi di Salerno, Via Ponte don Melillo, 84084 Fisciano (SA), Italy; e-mail: roberto.scarpa@sa.infn.it seismic energy (Ide et al., 2007a). These phenomena play an important role in stress redistribution and stress release along active faults.

Low frequency earthquakes and tremors, likely originated by fluid flows inside magma chambers and conduits, are traditionally observed in volcanic environments (Chouet, 1996). In the last decade a new category of low frequency seismic signals, called deep non volcanic tremor, has been discovered away from volcanoes along subduction zones of Japan (Obara, 2002), and subsequently along the west coast of North America, from California to British Columbia, Canada (Rogers and Dragert, 2003; Kao et al., 2006; Gomberg et al., 2008). In Japan a deep tremor is often associated with low frequency earthquakes of low magnitude (Shelly et al., 2007). Swarms of these events are related to tectonic activity of subduction 
zones and in particular to the creeping zones of these faults representing shear slip on the plate interface. In both Japan and Cascadia subduction zones, the major swarms of tremors, lasting from hours to weeks, are associated with slow slip located along the subduction plane, possibly connected to large and catastrophic earthquakes (Ide et al., 2007b). Along the Cascadia, these tremors occur every 13-16 months and have been related to the slip of a very large fault capable to generate a Magnitude 9 earthquake (Rogers and Dragert, 2003). This explains the increase in studies aimed at understanding the mechanisms of these events.

The Apennine mountain chain constitutes the most active seismogenetic region of Italy, capable to generate moderately large earthquakes of magnitude up to 7 (Boschi et al., 2000). The central segment of the mountain chain is affected by major seismicity associated

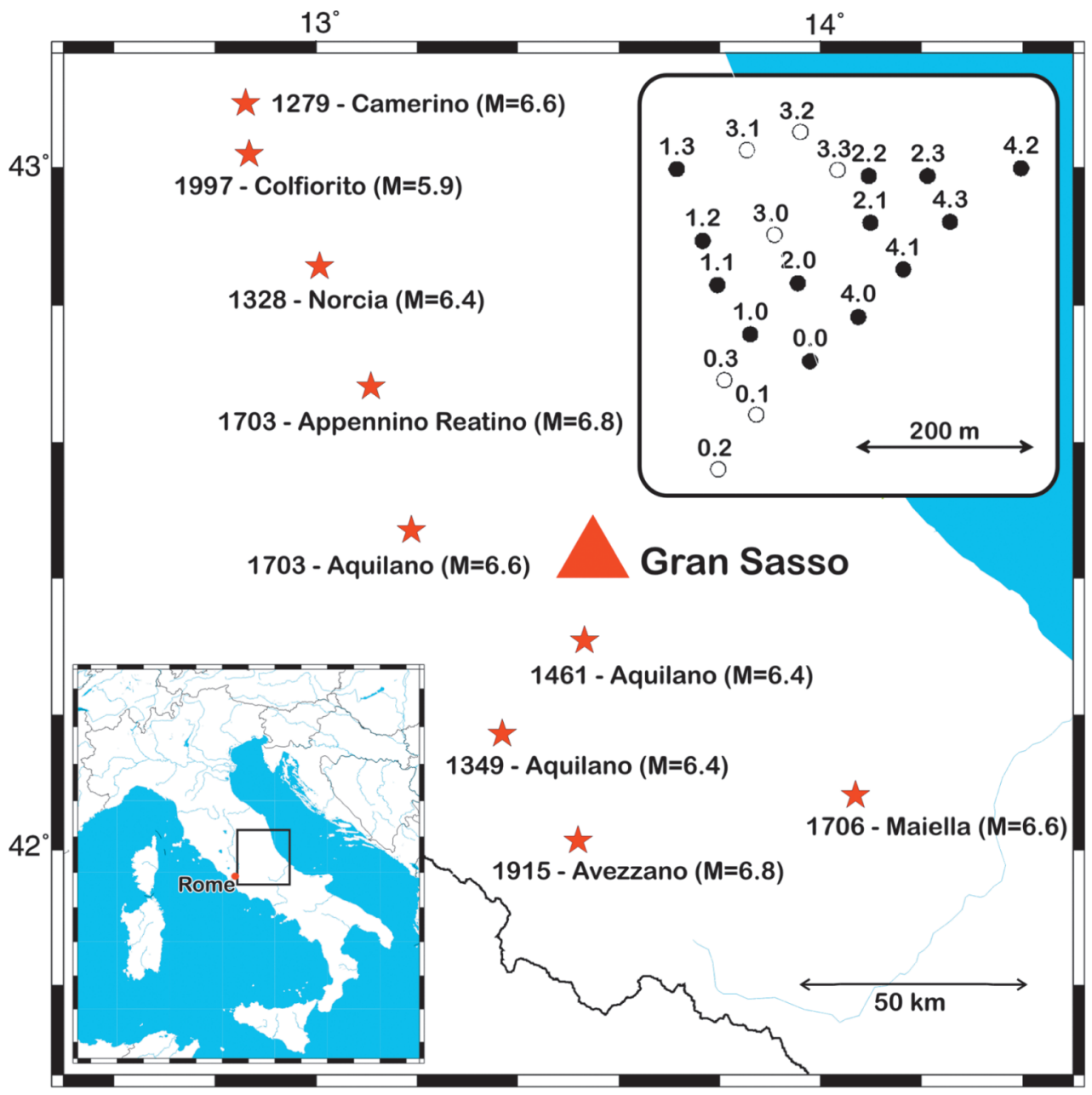

Fig. 1. Location of the underground laboratory of Gran Sasso in the central Italy and the epicenters of the most energetic earthquakes occurred in historical time. The insert shows the geometry of the UNDERground SEISmic array, black circles represent the array stations active in 2004. 
with the distensive tectonics governing the Apennines since the Late Pliocene. In this region, two geodetic interferometers located in an underground laboratory under the Gran Sasso massif (fig. 1) have recently allowed the discovery of very small slow earthquakes probably linked to the activity of a shallow fault (Crescentini et al., 1999; Amoruso et al., 2002). In the same tunnel a small aperture seismic array (Project UNDERSEIS), characterized by a low detection threshold, is also operating. The closest major historical event was the Ms=6.8 Avezzano earthquake, the occurred in 1915, which caused about 32,000 casualties in the region (Amoruso et al., 1998). In addition, low-tomoderate size earthquakes occur quite frequently in the region, the most recent in 1992, 1994 and 1996 (De Luca et al., 2000; Chiarabba et al., 2005). In the same area a temporary largescale seismic deployment was installed aimed at defining the location and geometry of seismogenic structures from microseismicity data (Chiarabba et al.,, 2005).

This paper illustrates the recent observations made in the seismic domain by using the very high sensitivity interferometers and seismic array.

\section{Instrumental facilities}

The Gran Sasso massif, located in central Italy about $120 \mathrm{~km}$ ENE of Rome (fig.1), constitutes the highest peak (2914 m) of the Apennines mountain chain. Since 1986, sub nuclear particle physics laboratories have been hosted in an underground tunnel systems located at a mean elevation of $960 \mathrm{~m}$, being therefore naturally shielded by a 1500 -m-thick limestone cap. In 1994 two long baseline laser interferometers, specifically designed for geophysical studies, became operative in the underground laboratory (Crescentini et al., 1997). Until 1999 the interferometer measured difference in extension between one 90 -m-long baseline oriented N66E and another 90-m-long baseline oriented N24W, i.e. one shear-strain component. Since 1999 independent extensions of the two $90 \mathrm{~m}$ orthogonal baselines of the interferometer are measured, thus allowing areal strain to be also revealed.

The low noise associated with the underground setting (De Luca et al., 1998), and the high potential seismicity make the Gran Sasso laboratory an ideal site for high resolution seismic observations. The design of the UNDERSEIS hardware and software components began in the late 90's. The array became operative by May, 2002, with on original configuration of 4 three-component seismometers. In its present configuration the array consists of 20 elements, each one equipped with a short period $(1 \mathrm{~Hz})$, three component Mark L4C-3D seismometer. Seismic signals are digitized at a sampling interval of $0.01 \mathrm{~s}$ with a nominal dynamic range of 24 bit, and the acquisition is continuous (Scarpa et al., 2004; Saccorotti et al., 2006). The UNDERSEIS array depicts an average sensor spacing of about $90 \mathrm{~m}$, while the largest distance among sensors is about $550 \mathrm{~m}$ (fig. 1). Location of the array elements was constrained by the geometry of the tunnel system, thus hindering the achievement of uniform station spacing and azimuths distribution which are warranted for multichannel analyses. The data collected at the UNDERSEIS array are stored in hour-long sac format files. Preliminary analysis aimed at the identification of potentially interesting events are automatically performed in near real time. UNDERSEIS is located close to a main seismogenetic fault where the slow earthquakes detected through the two geodetic laser interferometers probably occurred (Crescentini et al., 1999; Amoruso et al., 2002).

\section{Interferometric data}

Several clustered slow earthquakes have been observed from March to October 1997 by the interferometer (Crescentini et al., 1999). The swarm was preceded by a few events since the end of 1996, and was followed by other episodic events in the next few months. Slow earthquakes appear as nearly-exponential strain changes (fig. 2) with duration from tens to thousands of seconds and amplitudes of a few nanostrains (Crescentini et al., 1999).

The shear-strain components of three additional slow earthquakes recorded in May 2001 


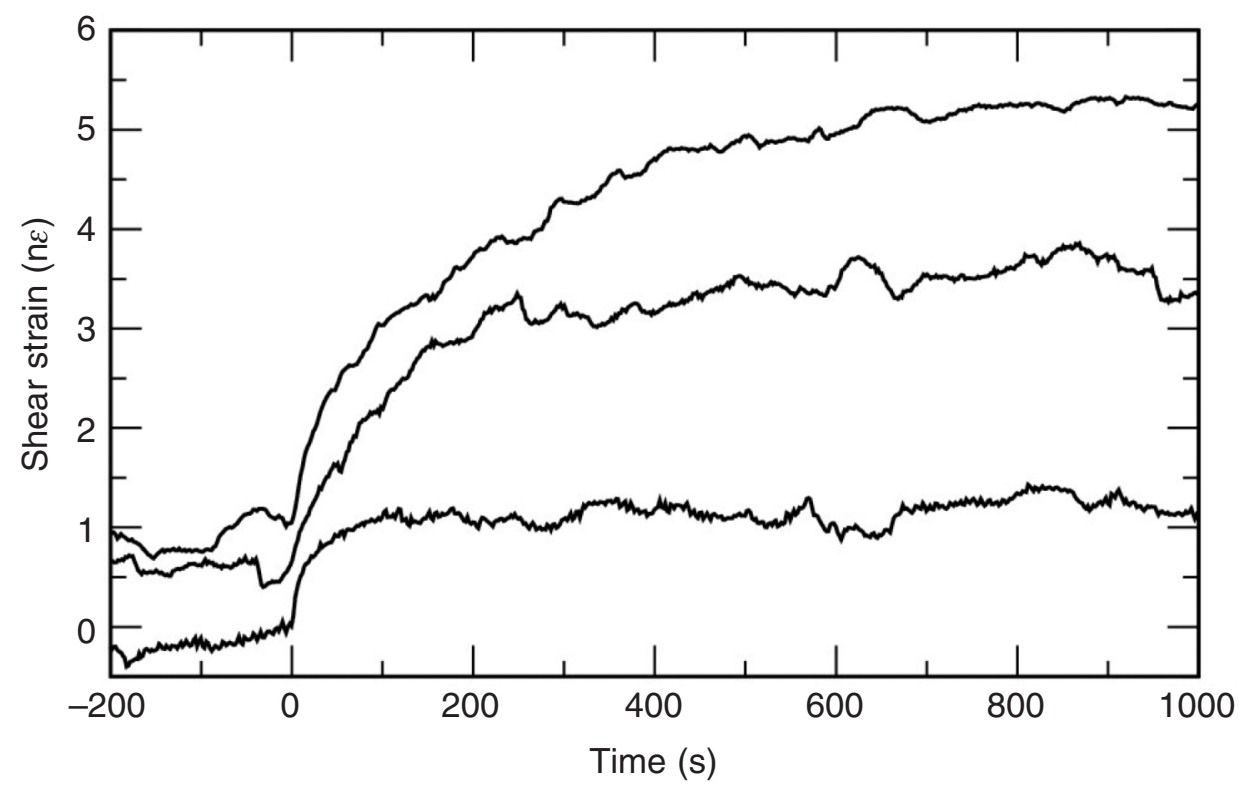

Fig. 2. Examples of slow earthquakes recorded at the Gran Sasso geodetic interferometer.

are very similar to that of the 1997 events, and therefore presumably originate on the same fault. All the 2001 events give negative (compressive) or undetectable areal strain. No clear signal related to the slow strain events is detectable in the seismic records at the verybroadband seismographic station AQU, located about $17 \mathrm{~km} \mathrm{SW}$ of the interferometer (Boschi and Morelli, 1994). Lack of detection at AQU suggests a very local source. Amoruso et al. (2002) attempted to constrain the source location showing that the favoured fault, although known to geologists and mapped in neotectonic maps of the area, has no known seismic behaviour. Few further slow events have been observed since then.

The slow earthquakes recorded in the central Apennines are however a quite rare phenomenon. In fact, apart the swarm recorded during 1997, only a few events have been recorded since 1994 to present. It is noteworthy that the 1997 swarm occurred in correspondence of the last activation of this seismogenic belt, culminated in the Colfiorito sequence with three events of magnitude close to 6 (Ekstrom et al., 1998, fig.1) and the cumulative number of slow events recorded by the interferometers closely resembles the cumulative number of regular earthquakes occurred in a radius of 200 $\mathrm{km}$ from the interferometer (see fig. 2 in Crescentini et al., 1999). We have also examined the distribution of delays between each slow earthquake and the nearest (in time) regular earthquake occurred within $200 \mathrm{~km}$ from the interferometers. In particular, we have considered the delay between each slow earthquake and the subsequent regular earthquake, between each slow earthquake and the preceding regular earthquake, and between each slow earthquake and the nearest (either preceding or subsequent) regular earthquake (fig. 3). In any case, the distribution is approximately an exponentially decreasing function, as expected for Poisson random processes, thus excluding a direct causeeffect relationship between regular earthquakes and recorded slow signals (e.g., non-linear response to seismic transit beneath the instruments). Space-time distributions of the slow earthquakes and of the ordinary seismic events and the lack of any cause-and-effect relation 


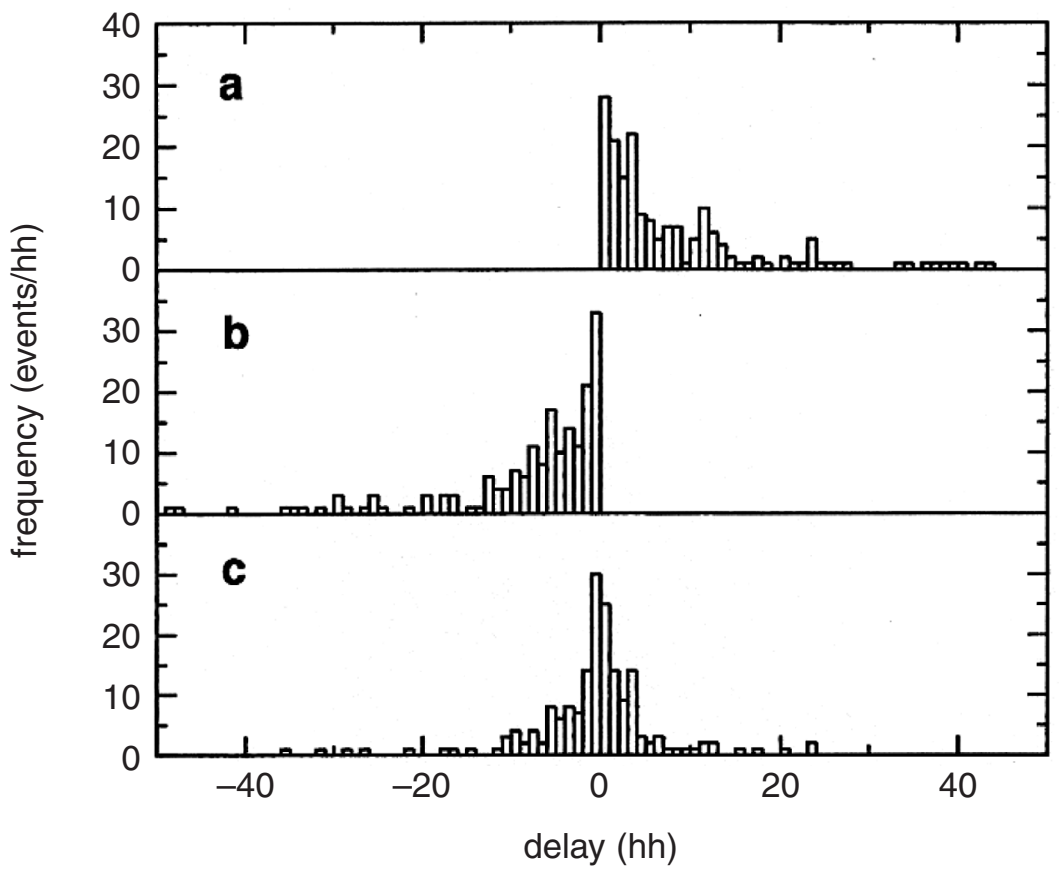

Fig. 3a-c. Distribution of delays between slow earthquakes and regular earthquakes occurred within $200 \mathrm{~km}$ from the laser interferometers: panel (a), delay between each slow earthquake and the subsequent regular earthquake; panel (b), delay between each slow earthquake and the precedine regular earthquake; panel (c), delay between each slow earthquake and the nearest (either precedine or subsequent) regular earthquake.

suggest that they may be the consequence of a single stress redistribution phenomenon affecting a large area of the Apennines.

\section{Seismic data}

The deep tremor observed in Cascadia and Japan is characterized by a small amplitude, not clear onset, absence of impulsive phases and frequency content usually in the band $1-8 \mathrm{~Hz}$ (La Rocca et al., 2005; Obara and Hirose, 2006). Most of these features are similar to the volcanic tremor but its occurrence is away from volcanoes and generally its location is at 20-70 $\mathrm{km}$ depths. The amplitude of these events rarely exceeds $1 \mathrm{micron} / \mathrm{s}$, therefore they are detectable only at very low noise sites. At the UNDERSEIS array the seismic noise is of the order of $0.1 \mathrm{micron} / \mathrm{sec}$ due to its underground lo- cation and thus this array provides an unique opportunity to detect the possible occurrence of this phenomenon in Italy.

The coherence of the seismic wavefield among the array stations (Foster and Guinzy, 1967; Vernon et al., 1991) has been computed for all data recorded since 2003. We estimated the coherence by computing the average value in the 1-8 Hz frequency band, and considering the mean among the three components and among the array stations.

The sliding window used in this analysis was 20.48 s (2048 samples) with 50\% overlapping. Many local and regional earthquakes, and any other potentially interesting signals highlighted by coherence higher than the background value, were analysed using the array methods in frequency domain Beam Forming and High Resolution (BF, HR, Rost and Thomas, 2002). Local and regional earthquakes 


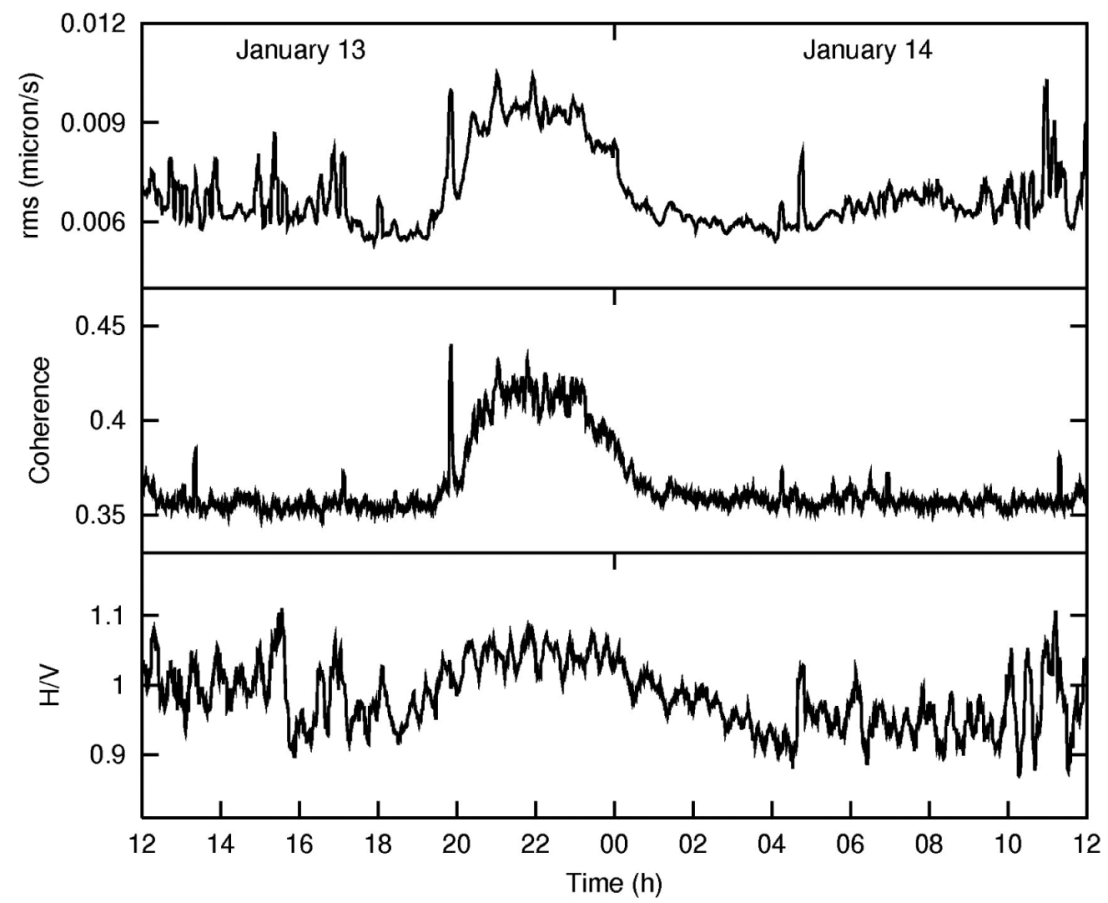

Fig. 4. Rms amplitude of the seismic signal (top plot), mean coherence among the three componente (middle plot) and $\mathrm{H} / \mathrm{V}$ ratio (bottom plot) computed in the frequency band $1-4 \mathrm{~Hz}$.

appear as high amplitude, short duration peaks in the coherence results. Only one different type of signal, characterized by duration of several hours (from about 19:00 of 13 January until 01:00 of 14 January, 2004), was evidenced by a coherence higher than the value corresponding to the seismic noise. Figure 4 shows the enhancement of the coherence, which rises clearly above the background value of about 0.35 for several hours. This unique episode was been recorded without the occurrence of any major local or regional earthquake. It is also noteworthy observing that data recorded by the interferometer do not show any signals above the noise threshold in the same time window.

At a visual inspection the seismograms show the presence of signals which are common to most of the stations, but characterized by an extremely low signal to noise ratio. Figure 5 shows $30 \mathrm{~s}$ of signals recorded at $21: 48$ by the NS components, filtered in the $1-3 \mathrm{~Hz}$ band. Spectra have been computed for both the low frequency signal and the seismic noise, taking the average among several windows recorded both before and after the interesting event (fig. 6). The spectral ratio indicates a frequency content between $1 \mathrm{~Hz}$ and $4 \mathrm{~Hz}$ (fig. 6) for the signal recorded between 19:00 and 01:00.

The rms of the stacked signals filtered in the same frequency band, 1-4 Hz, was computed for many hours, before, during and after the occurrence of the low frequency event. An example of stacked signal is shown at the bottom of fig. 5. The improvement in the SNR is evident in this seismogram, which highlights the short transients common to all stations. Stacked seismograms were used to compute the rms and the $\mathrm{H} / \mathrm{V}$ ratio over a $60 \mathrm{~s}$ sliding window, in order to follow the event evolution. The result, shown in fig. 4, demonstrates that the coherence increase follows very well the amplitude increase of the signal. The H/V ratio is characterized by 


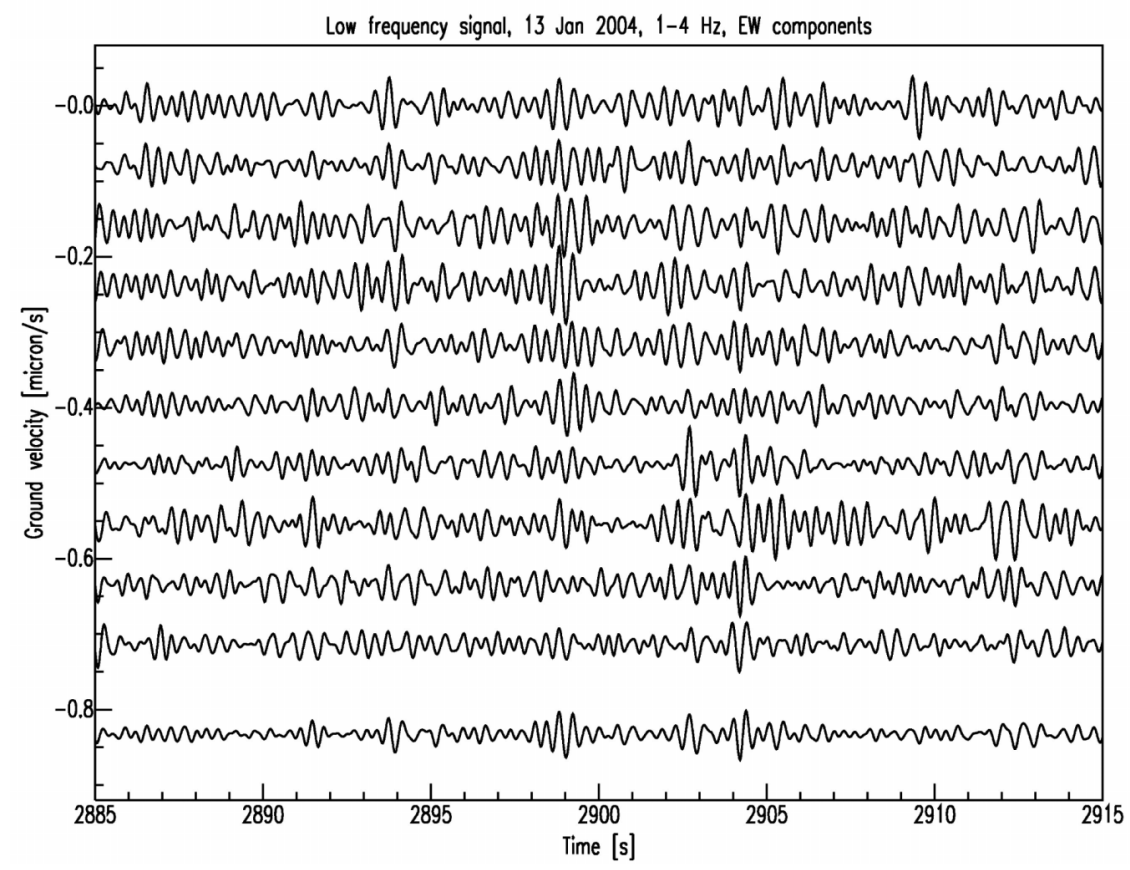

Fig. 5. Ten seismograms recorded by the EW components of array stations during the low frequency tremor episode occurred on 13 January 2004. The bottom trace is the signal stacking. All signals shown in figure have been filtered between $1 \mathrm{~Hz}$ and $4 \mathrm{~Hz}$. The short transients visible throughout the array signals appear more evident in the stacked signal, where the SNR is clearly enhanced.

a flat maximum with value slightly greater than 1 , but the irregular behaviour before the event does not allow any reliable conclusion (fig. 4). Most of the peaks in the rms signal correspond to local disturbances at some stations. Some common peaks in the rms and coherence time series are associated with local microearthquakes.

The high peak around 19:50, clearly visible in both signals, corresponds to a $\mathrm{M}=4$ earthquake occurred in Greece, $735 \mathrm{~km}$ from the array.

The coherence as a function of frequency has been computed for both the low frequency signal and the seismic noise recorded some hours before and after. The comparison between the two coherences, depicted in fig. 7 , shows the main differences in the same frequency band, 1-4 Hz. Array analysis has been performed in this frequency band using all available stations operating at that time. Results are characterized by low values of slowness, whose distribution is centred at about $0.2 \mathrm{~s} / \mathrm{km}$, while the backazimuth shows a highly scattered pattern with predominance of values in the north sectors (fig. 8). The comparison between results of array analysis applied to the low frequency tremor and to the seismic noise is shown in fig. 9.

The slowness distribution of the tremor indicates clearly that this signal is characterized by apparent velocity much higher than that observed for the seismic noise. The absence of impulsive phases in the signal does not permit an appropriate classification of the seismic waves. However, the high apparent velocity and the $\mathrm{H} / \mathrm{V}$ ratio greater than 1 indicate a predominance of shear waves impinging the array with a small incidence angle. Polarization analysis applied to the stacked seismograms yields re- 


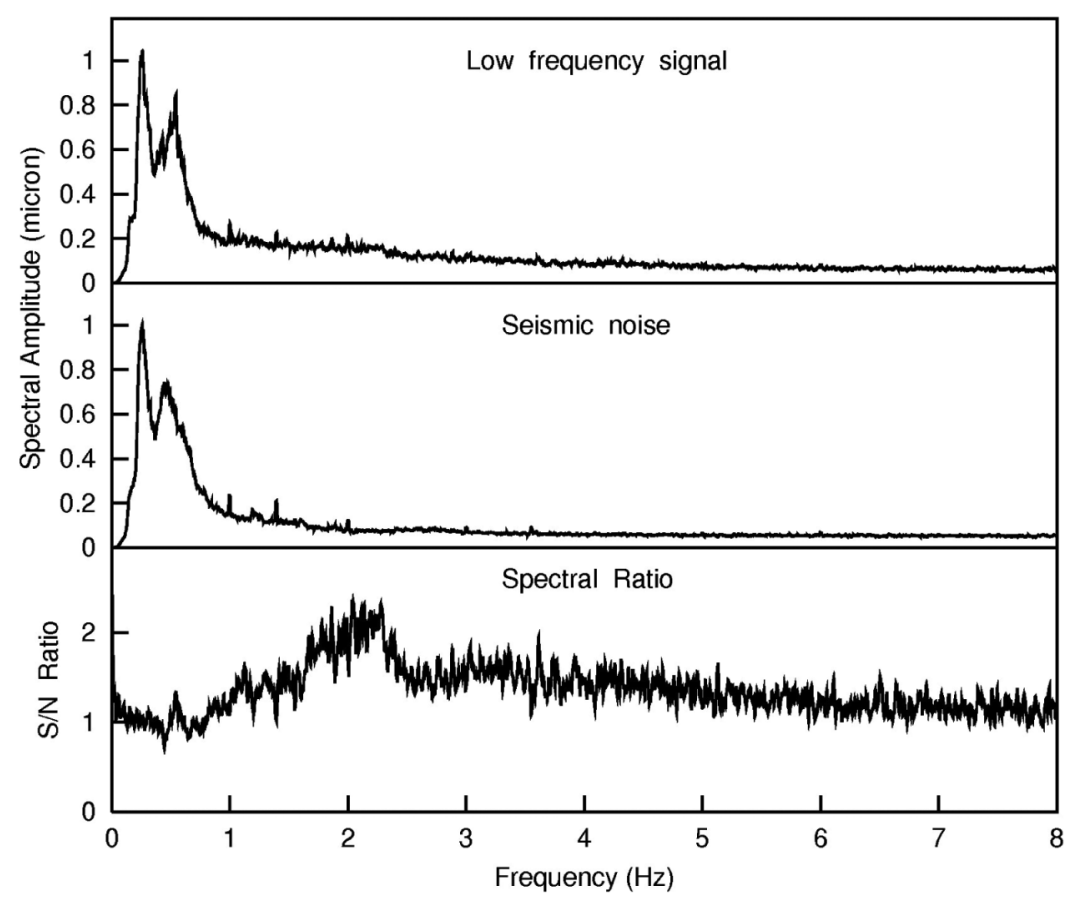

Fig. 6. Velocity spectra of the low frequency signal (top), of the seismic noise (middle plot), and spectral ratio between them (bottom).

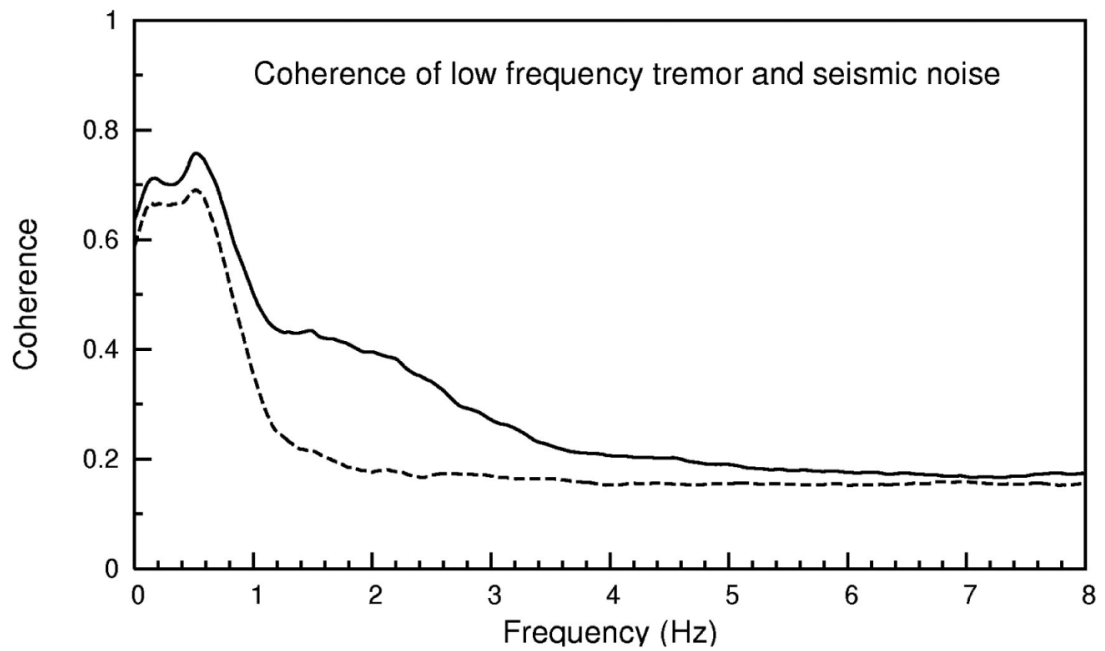

Fig. 7. Comparison of the coherence as function of frequency computed for the low frequency signal (continuous line) and for seismic noise (dashed line). The major differences appear in the frequency band $1 \mathrm{~Hz}-4 \mathrm{~Hz}$, which is roughly the same band evidenced by the spectral ratio shown in fig. 6 . 
Array analysis of the low frequency event $20040113,21: 00-22: 00$, EW, coherence threshold $0.5, f=2.5 \mathrm{~Hz}$

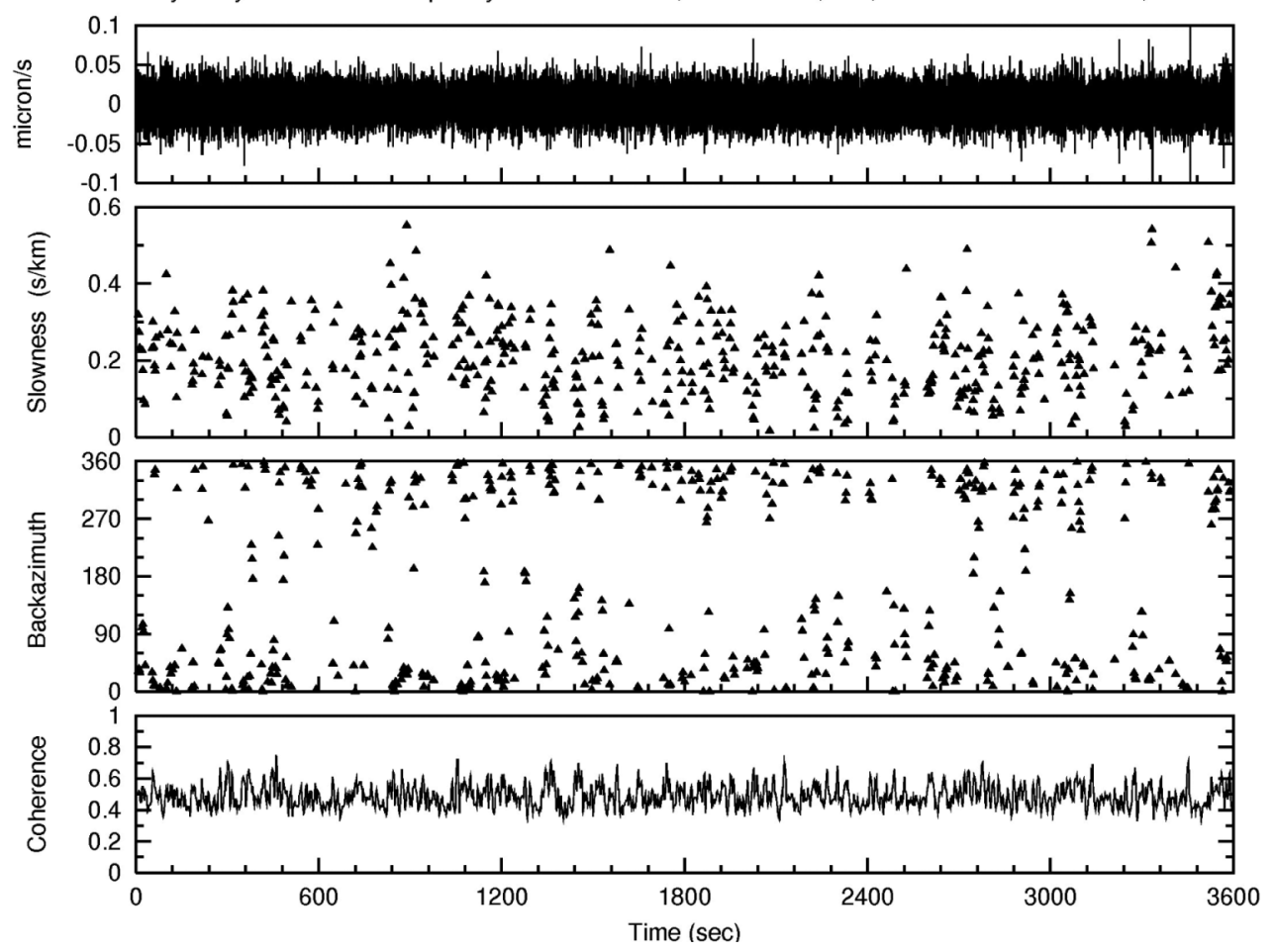

Fig. 8. Results of array analysis in the frequency domain applying the Beam Forming method to the EW components. Top plot shows the stacked EW seismogram, then slowness, backazimuth and coherence of the wavefield are shown for one hour of signals, from 21:00 to 22:00. In the second and third plots only results relative to windows characterized by coherence higher than 0.5 have been plotted.

sults much more stable than the single station analysis, as expected. The distribution of polarization azimuth, shown in fig. 9, is strongly anisotropic, being the NE-SW direction observed with very high probability while the NW-SE particle motion is completely absent in the wave field. Unfortunately, this pattern is observed very often at the UNDERSEIS array, even for the seismic noise, thus suggesting a local site or propagation effect unrelated with the low frequency tremor.

The low frequency event recorded on January 13-14 2004 has many features similar to the deep tremor observed in other regions around the world, such as the low amplitude, low frequency contents, duration of hours. However, the very low SNR does not allow a detailed characterization of the seismic wave field, essential to infer on the nature and origin of this event.

\section{Conclusions}

An expanding variety of unusual earthquakes has recently been discovered, such as silent earthquakes, low frequency earthquakes, low frequency tremor, slow slip events and very low frequency earthquakes. These events have been reported to occur at the same time and location suggesting a close relationship and perhaps a common source mechanism. They have much longer durations than ordinary earthquakes of comparable seismic moment. Ide et 

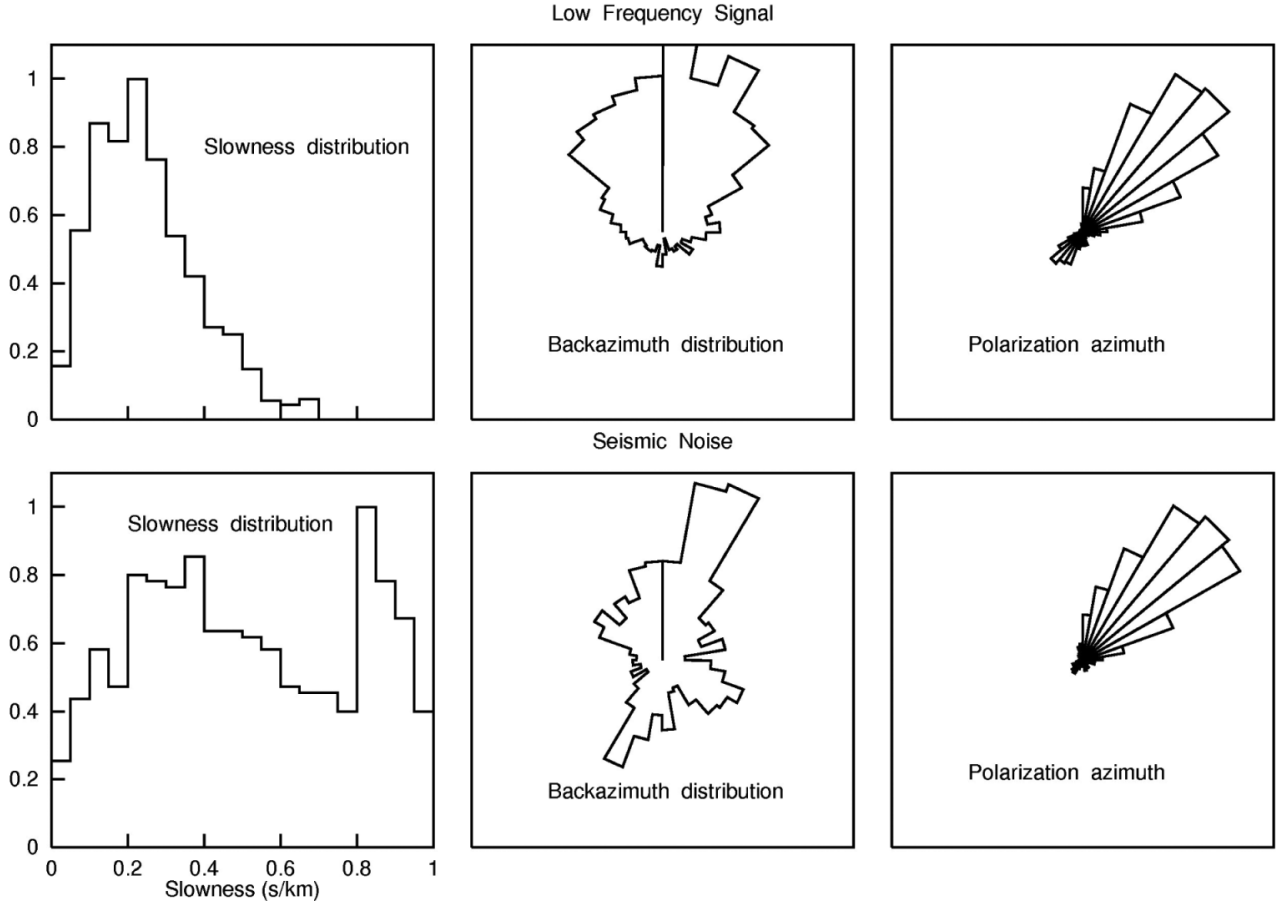

Fig. 9. Normalized distributions of slowness (left), backazimuth (middle) and polarization azimuth (right) obtained by the analysis of the low frequency tremor (top plots) and seismic noise (bottom).

The distributions of slowness and backazimuth, which depends on the propagation characteristics of the wave field, are completely different in the two cases. On the contrary, the polarization azimuth is very similar for both the low frequency tremor and the seismic noise.

al. (2007a) have shown that these slow events follow a simple, unified scaling relationship that clearly differentiates their behaviour from that of regular earthquakes. Their seismic moment is proportional to the characteristic duration and their moment rate function is constant, with a spectral high-frequency decay of $f^{-1} \mathrm{~Hz}$. This scaling and spectral behaviour indicates that they can be thought of as different manifestations of the same phenomena and that they comprise a new earthquake category. The observed scale dependence of rupture velocity for these events can be explained by either a constant low-stress drop model or a diffusional constant-slip model (already proposed in the $1 \mathrm{D}$ case by Amoruso et al. 2004). This new scaling law may unify a diverse class of slow seismic events and lead to a better understand- ing of the plate subduction process and large earthquake generation, but different models have also been proposed (Schwartz et al., 2007).

The occurrence of slow earthquakes with a mechanism similar to that proposed by Ide et al (2007a) was found in central Apennines by Crescentini et al. (1999). These small slow earthquakes produce neither surface deformations detectable by GPS or other current geodetic technique, nor seismic waves detectable by usual seismometers or easily recognized in seismograms. Only the very high sensitivity laser interferometers, located in an underground domain, permitted the observation of such events. The Gran Sasso area does not show significant instrumental or historical records of seismicity but only paleoseismicity. The activi- 
ty we recorded probably originated on a fault which very likely did not exhibit seismic activity in historical time. This is a significant difference with respect to other reported slow ruptures where slow earthquakes have generally occurred on faults which also show seismic activity. This observation may suggest the existence of different modes of rupturing of the same structure and that deformation developed through slow fracturing represents an intermediate mode between seismic activity and creeping (Linde et al., 1996). In our case evidence suggests that the fault is currently failing exclusively through slow fracturing. At least, this has been the only activity during the sequence we documented. This fact may have important consequences on evaluating seismic hazard: a fault rated as active on geological grounds, may indeed be so. Yet its activity may be totally in the slow earthquake band, with no response in the seismic band of the spectrum. It is clear then that very-low frequency, high-sensitivity records of ground deformation contribute essential data to improve the real-time picture of seismic activity and this is presently done by the high performance and sensitivity of the UNDERSEIS project.

The anomalous coherent seismic tremor event occurred on January 13, 2004 may be related to the occurrence of a non volcanic tremor episode. However the small amplitude of this signal does not allow to infer more details that can help in understanding its source process. At the end of 2007 the amplifiers gain of the seismic instruments have been increased by two order of magnitude in order to further improve the capability to detect very small signals. Further experimental work will be of great help to understand if the tremor episodes can be recorded in the peculiar tectonic domain of the Apennines. Our present observations suggests the absence of any correlation between slow earthquakes and the tremor episode in the Apennines.

\section{Acknowledgements}

The authors thanks G. Saccorotti and an anonymous referee which helped in improving the quality of the manuscript. This work has been conducted in the framework of the program agreement between INGV-Osservatorio Vesuviano and Istituto Nazionale di Fisica $\mathrm{Nu}-$ cleare. We also acknowledge partial support from MIUR-PRIN2005 project «Analisi e modellistica dei processi sismici e deformativi dell'Appennino centrale».

\section{REFERENCES}

Amoruso, A., L. Crescentini, A. Morelli and R. Scarpa (2002): Slow rupture of an aseismic fault in a seismogenic region of Central Italy, Geophys. Res. Lett., 29 (24), 2219, doi: 10.1029/2002GL016027.

Amoruso, A., L. Crescentini, M. Dragoni and A. Piombo (2004): Fault slip controlled by gouge rheology: A model for slow earthquakes, Geophys. J. Int., 159, 347352.

Boschi, E. and A. Morelli (1994): The MEDNET program, Ann. Geofis., XXXVII, 1066-1070.

Boschi, E., E. Guidoboni, P. Ferrari, G. Mariotti, G. VALENSISE and. P. GASPERINI (2000): Catalogue of strong Italian earthquakes, 461 B.C. to 1997, Ann. Geophys., 43 (4), 609-868.

Chiarabba, C., L. Jovane and R. Di Stefano (2005): A new view of Italian seismicity using 20 years of instrumental recordings, Tectonophysics, 395, 251-268.

Chouet, B.A. (1996): Long-period volcano seismicity: its source and use in eruption forecasting, Nature, 380, 309-316.

Crescentini, L., A. Amoruso, G. Fiocco and G. Visconti (1997): Installation of a high-sensitivity laser strainmeter in a tunnel in Central Italy, Rev. Scient. Instrum., 68, 3206-3210.

Crescentini, L., A. Amoruso and R. Scarpa (1999): Constraints on slow earthquakes dynamics from a swarm in Central Italy, Science, 286, 2132-2134.

De Luca, G., E. Del Pezzo, F. Di Luccio, L. Margheriti, G. Milana and R. ScARPA (1998): Site response study in Abruzzo (Central Italy): underground array versus surface stations., J. Seismol., 2, 223-236.

De Luca, G., R. Scarpa, L. Filippi, A. Gorini, S. MarcuCCi, P. Marsan, G. Milana and E. Zambonelli (2000): A detailed analysis of two seismic sequences in Abruzzo, central Apennines, Italy, J. Seismology, 4, 1-21.

Ekström, E., A. Morelli, E. Boschi and A.M. DziewonsKI (1998): Moment tensor analysis of the Central Italy earthquake sequence of September-October 1997, Geophys. Res. Lett. 25, 1971-1974.

Foster, M. R. and N. J. GuINZY (1967): The coefficient of coherence: its estimation and use in geophysical data processing, Geophysics, 22, 602-616.

Gomberg, J., J. L. Rubinstein, Zhigang Peng, K. C. CreaGER, J. E. VIDALE and P. BodIN (2008): Widespread Triggering of Nonvolcanic Tremor in California, Science, 319, 173, doi: 10.1126/science.1149164 .

IDE, S., G. C. BEROZA, D.R. ShElly and T. UChide (2007a): A scaling law for slow earthquakes, Nature, 447, 7679, doi:10.1038/nature 05780 . 
IDE, S., D. R. Shelly and G. C. Beroza (2007b): Mechanism of deep low frequency earthquakes: Further evidence that deep non-volcanic tremor is generated by shear slip on the plate interface, Geophys. Res. Lett., 34, L03308, doi:10.1029/2006GL028890.

Kao, H., S.-J. Shan, H. Dragert, G. Rogers, J. F. Cassidy, K. WANG, T. S. JAMES and K. RAMACHANDRAN (2006): Spatial-temporal patterns of seismic tremors in northern Cascadia. J. Geophys. Res., 111, B03309, doi:10.1029/2005JB003727.

La Rocca M., W. McCausland, D. Galluzzo, S. MaloNe, G. Saccorotti and E. Del Pezzo (2005): Array measurement of deep tremor signals in the Cascadia subduction zone, Geophys. Res. Lett., 32, doi:10.1029/ 2005GL023974.

Linde, A.T., M.T. Gladwin, M.J.S. Johnston, R.L. GWYTHER and R.G. BILHAM (1996): A slow earthquake sequence on the San Andreas fault, Nature, 383, 65-68.

ObArA, K. (2002): Nonvolcanic deep tremor associated with subduction in Southwest Japan, Science, 296, 1679-1681, doi: 10.111/science.1070378.

Obara, K. and H. Hirose (2006): Non-volcanic deep lowfrequency tremors accompanying slow slips in the southwest Japan subduction zone, Tectonophysics, 417, 33-51.
Rogers, G. and H. Dragert (2003): Episodic tremor and slip on Cascadia subduction zone: the chatter of silent slip, Science, 300, 1942-1943.

Rost, S. and S. Thomas (2002): Array seismology: methods and applications, Rev. Geophysics, 40, 1008, doi:10.1029/2000RG000100.

Saccorotti, G., B. Di Lieto, C. Fischione, F. Tronca and R. SCARPA (2006): Performances of the UNDERground SEISmic array for the analysis of seismicity in Central Italy, Annals of Geophysics, 49, 1055-1071.

Scarpa, R., R. Muscente, F. Tronca, C. Fischione, P. Rotella, M. Abril, G. Alguacil, W. De Cesare and M. MARTINI (2004): UNDERSEIS: The Underground Seismic Array, Seismol. Res. Lett., 75, 493-504.

Shelly, D. R., G.C. Beroza and S. Ide (2007): Non-volcanic tremor and low frequency earthquake swarms, Nature, 446, 305-307, doi:10.1038/nature05666.

Schwartz, S. Y., J. M. ROKOSKY and K. OBARA (2007): Scaling Relationships for Slow Slip Events and Tremor in Subduction Zones, Eos Trans. AGU, 88 (52), Fall Meet. Suppl., Abstract T13F-02.

Vernon, F. L., J. Fletcher, L. Carrol, A. Chave and E. SEMBERA (1991): Coherence of Seismic Body Waves From Local Events as Measured by a Small Aperture Array, J. Geophys. Res., 96. 